CATALAN REVIEW

Catalan Review

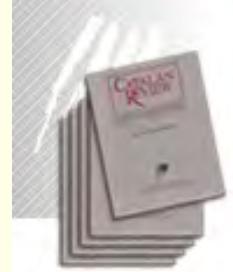

You are accessing the Digital Archive of the Catalan Review Journal.

By accessing and/or using this Digital Archive, you accept and agree to abide by the Terms and Conditions of Use available at http://www.nacs-

catalanstudies.org/catalan review.html

Catalan Review is the premier international scholarly journal devoted to all aspects of Catalan culture. By Catalan culture is understood all manifestations of intellectual and artistic life produced in the Catalan language or in the geographical areas where Catalan is spoken. Catalan Review has been in publication since 1986.
NORTH

AMERICAN

CATALAN

SOCIETY
Esteu accedint a l'Arxiu Digital del Catalan Review

A l' accedir i / o utilitzar aquest Arxiu Digital, vostè accepta i es compromet a complir els termes i condicions d'ús disponibles a http://www.nacs-

catalanstudies.org/catalan review.html

Catalan Review és la primera revista internacional dedicada a tots els aspectes de la cultura catalana. Per la cultura catalana s'entén totes les manifestacions de la vida intel lectual i artística produïda en llengua catalana o en les zones geogràfiques on es parla català. Catalan Review es publica des de 1986.

\title{
Del desert a la terra promesa: 40 anys de literatura dramàtica a Barcelona Josep Maria Benet i Jornet
}

Catalan Review, Vol. XVIII, number 1-2, (1998), p. 231-236 


\section{DEL DESERT A LA TERRA PROMESA: 4O ANYS DE LITERATURA DRAMÀTICA A BARCELONA}

JOSEP MARIA BENET I JORNET

\section{ABSTRACT}

Celebrated playwright Josep Maria Benet i Jornet offers a personally inflected overview of the last forty years of theater in Catalonia. A strong defender of textually based productions, Benet notes that the Catalan language, marginalized under Franco, does not exactly come booming center stage once the dictator disappears. Whether in its strictly commercial or more experimental and independent forms (or in combinations thereof), theater in Catalonia appeared to have little room for Catalan authors, living or dead. By the mid-1980s, however, the situation had changed, and the authors of theatrical works (Sergi Belbel, Lluïsa Cunillé, Carles Batlle, Jordi Galzeran, Jordi Sànchez, and others) were once again in demand in alternative, private, and public venues.

$\mathrm{El}_{1}$ segon llibre de la Bíblia es diu "Èxode”. Com sabeu, en ell s'explica que els jueus van fugir de la captivitat que patien a Egipte i van viatjar durant quaranta anys pel desert, perduts i a la recerca de la Terra Promesa - una terra que sovint dubtaven de poder abastar mai. Però hi van arribar. Encara que arribar-hi, contra allò que havien imaginat, no va ser el final feliç de la seva història. Va ser el començament de noves lluites externes i de nous conflictes interns. Bé, voldría establir un paral-lelisme esquemàtic i frívol - ho sé- entre aquella travessa del desert $\mathrm{i}$ la història del teatre de text a Barcelona durant els últims 40 anys. El teatre català, a Barcelona, el seu centre principal d'activitat (però no l'únic, per descomptat), ha viscut, al llarg de quaranta anys, una trajectòria potser una mica diferent de la que han sofert l'assaig, la narrativa o la poesia, i completament diferent de l'arquitectura, de la pintura o de la música, que són arts que necessiten un llenguatge determinat, però no cap llengua concreta per expressar-se.

Al llarg dels anys quaranta, cinquanta i seixanta del segle xx la situació del teatre a Barcelona era semblant a la de qualsevol altra manifestació cultural de la resta de l'Estat espanyol, És a dir, sobrevivia com podia sota un govern antidemocràtic, de censura rígida i de reaccions contradictòries. Els espectacles que pujaven als escenaris barcelonins eren, amb excepcions, especialment desastrosos: textos 
dolents i mal escenificats, sense cap ambició estètica o dramàtica. $\mathrm{A}$. Madrid, per entendre'ns, es feia un teatre generalment mediocre, però tot i així molt millor que el que es veia a Barcelona. Malgrat això hi havia a Barcelona i a Catalunya en general autors que, d'amagat, com si fos un delicte, escrivien obres ambicioses, relacionables amb el teatre més ambiciós d'Europa; però aquestes obres no s'estrenaven i rarament es publicaven. $\mathrm{O}$, en els millors dels casos, es representaven una o dues vegades, en algun local no pròpiament teatral, fíns $i$ tot en domicilis particulars.

A finals dels anys cinquanta $\mathrm{i}$ a principis dels seixanta, quan les condicions polítiques i socials es van fer una mica més flexibles, va ser possible una progressiva reacció. Poc a poc es va formar un moviment teatral que va rebre el nom de "Teatre Independent". Aquesta nova manera de fer teatre va ocupar, per dir-ho amb un terme no exacte però entenedor per a tots, alguns locals off-off. Es tractava de la unió de grups d'actors, directors i escenògrafs, que no comptaven amb medis econòmics, però que, malgrat aixô, van emprendre la tasca de fer un teatre molt més ambiciós que aquell que es veia als pocs teatres comercials (privats) de la ciutat. El més interessant d'aquests grups va ser l'Escola d'Art Dramàtic Adrià Gual (EADAG). Era una escola de teatre, sí, però també alguna cosa més. Va ser en aquesta escola, a la qual vaig acudir durant un temps, on vaig sentir parlar, sovint per primera vegada, dels darrers i més atrevits moviments teatrals occidentals. I sobretot, els alumnes posàvem en escena, gairebé sempre utilitzant el català, en sessions obertes al públic, una considerable quantitat d'espectacles teatrals basats en textos de primera categoria, catalans o estrangers, clàssics o moderns. Recordo haver participat en obres de Salvador Espriu, de Ionesco, de Bernard Shaw, de Shakespeare i de Büchner.

Mentre aquest i tants d'altres grups de teatre lluitaven per imposar una mirada nova sobre el fet escènic, el teatre comercial a penes atreia ja cap mena de públic i agonitzava ràpidament. La travessa del desert va ser dura per a la cultura en general i també, per tant, per tota la professió teatral, però encara ho va ser més per als autors, per als escriptors de literatura dramàtica. Dins del "Teatre Independent", directors, escenògrafs $\mathrm{i}$ actors van anar aprenent formes renovadores, diferents, de l'ofici teatral. Però, amb excepcions, els nous autors teatrals joves no vam ser considerats, per aquests companys, dignes de participar en l'aventura. Directors, escenògrafs i actors van decidir que només havien d'exercitar-se a través de textos estrangers acreditats i madurs, clàssics o actuals. Els autors catalans, vius o morts, vam quedar apartats de l'aventura. Directors, escenògrafs $\mathrm{i}$ actors podien equivocar-se, rectificar $\mathrm{i}$ avançar en el seu coneixement dels mecanismes teatrals. Els autors - nosaltres - no. 
De fet el problema no era exclusiu de Barcelona. Des de finals dels anys seixanta, a la majoria dels països occidentals, no tant a la Gran Bretanya, però sí a la resta d'Europa, a França, Alemanya, Itàlia, Polònia, etc, $i$ en part també als EUA $i$ a Llatinoamèrica, van irrompre nous moviments teatrals, noves maneres de veure el fet teatral, que tenien un denominador comú: $s^{\prime}$ havia de prescindir de l'escriptor de literatura dramàtica. L'autor era una figura innecessària. Calia preparar els espectacles prescindint d'un text previ. I cal ser justos: aquests moviments van esdevenir fèrtils i enriquidors. Mentre, el "Teatre inde-

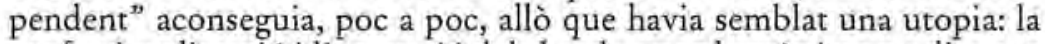
professionalització i l'ocupació dels locals teatrals pròpiament dits que quedaven a Barcelona. L'any 1976 es va crear el Teatre Lliure, petit edifici teatral on una companyia sorgida del "Teatre Independent" es va professionalitzar i va començar a capgirar de manera esplèndida l'art escènic a Barcelona.

Posaré un exemple personal. L'any 1977 vaig escriure una obra de teatre destinada a set actors amics. Vaig parlar amb dos dels directors del Teatre Lliure i van decidir que, si nosaltres trobàvem finançament i un escenari, ells la muntarien. No la muntarien dins del mateix Teatre Lliure - un text català no podia ser prou bo per ser representat al Lliure-però la muntarien. Ens va costar un any trobar els diners $i$ un bon escenari, un any durant el qual el prestigi del Lliure es va anar afermant. Vam aconseguir diners i escenari, un molt bon escenari. Però pocs dies abans de començar els assaigs, els directors del Lliure em van cridar i em van dir que no volien treballar amb la meva obra. I ens van abandonar. L'obra la va dirigir un altre director i vam aconseguir un bon èxit, però sigui com sigui, es va fer evident la conclusió que jo no era digne del Lliure - ni jo ni els altres autors vius i més o menys joves.

La part de desert que ens va tocar als autors era la més erma. Uns quants van desistir $\mathrm{i}$ van desaparèixer en tant que autors. Altres vam resistir. A partir de l'experiència del Lliure i de la d'altres noves companyies paral-leles, el teatre català va anar aconseguint, amb passes ràpides, una certa maduresa en la presentació d'obres de text. I també va aconseguir el respecte d'Europa. Els anys d'aprenentatge no havien estat estèrils: donaven fruits. Barcelona, amb el teatre català, es posava, de mica en mica, al capdavant de la renovació teatral a l'estat espanyol. Tots els components de la professió de l'espectacle van participar en aquesta renovació: tots menys, repeteixo, els autors.

Però finalment la situació va canviar també en aquest punt. A partir, més o menys, de 1986, la situació de la figura de l'autor va donar un nou tomb. Europa va reivindicar, de sobte, el retorn d'una determinada complexitat textual que només semblava possible amb la presència de l'escriptor de literatura dramàtica. Els autors tornàvem a ser neces- 
saris, Pocs vam arribar a la terra promesa però alguns, tanmateix, ho vam aconseguir. I a partir d'aleshores les coses han estat diferents.

Així, i torno al meu cas personal, el 1987 , deu anys després que les portes del Lliure se m'haguessin tancat, el director d'aquest mateix Teatre va presentar públicament excuses per haver oblidat fins aleshores els autors del país, i a mi em va demanar l'última obra que havia escrit. Per primer cop un ja no tan jove autor català estrenava al Lliure. I vaig tornar a estrenar-hi en més ocasions. La nostra situació fa temps que, més o menys, s'ha normalitzat.

He parlat molt del Lliure perquè va ser i és un teatre emblemàtic, però evidentment a Barcelona hi ha molts més teatres i companyies. De fet, el seu número ha augmentat de manera considerable al llarg dels últims vint anys. En els moments més negres hi va arribar a haver a Barcelona només unes deu sales. Ara n'hi ha unes trenta-cinc. Els equipaments tècnics han millorat de manera decisiva i fins alguns cinemes s'han convertit en teatres. A mitjans dels anys vuitanta la vida teatral de Barcelona aconseguia una força com no s'havia conegut des de principis del segle xx. Sospito que Barcelona es va convertir, de fet, en la ciutat de l'Estat Espanyol amb una vida teatral més activa $i$ ambiciosa.

Quina és la situació actual, a començaments del segle XXI? Doncs, hi ha tres tipus de teatres: alternatius (off-off), privats i públics. Els teatres alternatius són locals petits on, en els millors dels casos, es $\mathrm{fa}_{\mathrm{a}}$ una mena de treball de laboratori, es proven autors nous, s'importen autors estrangers desconeguts o s'experimenten fórmules dramàtiques noves. Sobreviuen gràcies a les subvencions de les institucions públiques. Els teatres privats ara estan en mans dels descendents del "Teatre Independent". En ells s'hi fa teatre més o menys comercial. El nivell de qualitat d'aquests teatres, l'única mena de teatres que existien abans, és incomparablement millor que el que tenien fa vint-i-cinc anys. Encara que siguin privats reben subvencions de les institucions públiques. Finalment, els teatres públics són el Teatre Nacional de Catalunya, el Teatre Lliure, l'anomenat Mercat de les Flors, i el Teatre del Liceu (òpera); pagats per l'Ajuntament, pel govern de Catalunya o per l'Estat, mantenen els equipaments de teatre més complexos, cars i ben equipats de la ciutat. Al costat de les companyies que viatgen per tot el món amb espectacles molt visuals, espectacles que constitueixen l'aspecte del teatre català encara més conegut fora de les nostres fronteres - Els Joglars, La Fura dels baus, Els Comediants, etc.- existeix avui un teatre de text de nivell comparable al de qualsevol altra dramatúrgia europea o també americana, dels EUA o d'Argentina.

Però, i els escriptors de literatura dramàtica, en definitiva? Tornaré enrere. Els autors que van aparèixer a finals dels anys seixanta i que no van aconseguir integrar-se al moviment del teatre independent tenien maneres d'escriure ben diferents les unes de les altres, però a 
tots ens unia allò que consideràvem un deure: mostrar amb les nostres obres la dura realitat social que ens envoltava i que el govern amagava. La majoria, per burlar el control de la censura, vam parlar de Barcelona, de Catalunya i de l'Estat Espanyol a través de paràboles que el públic sabia interpretar, que sabia descodificar i entendre. En casos molt aillats vam preferir la utilització d'un realisme més o menys directe. Per dir-ho de manera esquemàtica i per tant no exacta, la gran influència que va gravitar damunt d'aquesta generació va ser la de l'alemany Bertolt Brecht i, més enllà, en general, la del teatre alemany d'aquell moment. Alexandre Ballester, Jordi Teixidor, Jaume Melendres, Xavier Romeu, Rodolf Sirera o jo mateix formàvem part d'aquest grup. Al desert, com he explicat, pocs d'entre ells vam sobreviure.

Fem un gran salt i, deixant de banda quantitat d'autors que van aparèixer amb posterioritat, situem-nos en l'actualitat, en aquest moment de certa normalitat teatral i, per tant, també, de certa normalitat dramatúrgica que estem vivint i que va començar a configurar-se a partir de la meitat dels vuitanta. Avui els autors ens trobem vivint dins de la terra promesa, una terra que, recordem-ho, ofereix també problemes i fins i to perills. (Hi ha dificultat per fer-se escoltar i ser respectat quan has estrenat una primera obra i vols mostrar la segona, o també hi ha dificultat per fer-se escoltar quan algú considera que d'obres, ja n'has escrit massa. No entraré en aquests problemes perquè són comuns a totes les dramatúrgies del món, i perquè, en tot cas, hi ha uns quants autors que estrenem de manera regular.)

Vivim dins d'una certa normalitat. Això no vol dir tan sols que uns quants autors estrenem de manera assidua, també vol dir que escrivim amb una àmplia varietat de tècniques i d'intencions. Hi ha els que prefereixen crear formes experimentals, amb complexitats de laboratori i de cara a un públic minoritari; hi ha els que prefereixen crear textos de factura més simple, més lineals, oberts a l'èxit que proporciona un públic divers i ampli. En una zona intermèdia -i parlo de manera sempre esquemàtica - hi ha també els que mantenen un determinat grau d'ambició temàtica i formal però que al mateix temps busquen fórmules que els permetin ser escoltats per una quantitat de públic considerable.

Sobre les formes de dramatúrgia tradicional no sembla necessari fer aclariments. Entre les innovadores podriem citar: la influència del minimisme (pocs elements, però rics en components semàntics); l'ús del principi de fragmentaritat (eliminació d'escenes preparatòries o de transició, per exemple); l'atenció als processos receptius i a l'actitud activa de l'espectador potenciant els buits; les provocatives el-lipsis del text; la indeterminació dels llocs de l'acció i de la identitat mateixa dels personatges, i solucions híbrides que interrelacionen text $\mathrm{i}$ imatge.

Pel que $\mathrm{fa}$ a les temàtiques preferides, a diferència del que passava 
fa vint anys i més, quan la consideració del problemes col-lectius semblava manar de manera inexorable, ara es posa una particular atenció a les expressions afectives, al neguit existencial, a la incomunicació. La temàtica social, tanmateix, sobreviu, sense exclusions, en alguns dels autors. Temes com el mestissatge, la globalització o la recerca de la pròpia identitat conformen una part bel-ligerant i no pas petita d'aquestes dramatúrgies.

Els autors que escrivim avui, a diferència dels nostres predecessors, hem pogut obrir-nos a Europa, immergir-nos en Europa, i no necessitem sentir cap complex d'inferioritat davant les dramatúrgies d'altres països. En sentits ben diversos, dramaturgs estrangers com Beckett, Pinter, Bernhard, Mülller, Mamet i Koltès formen part dels nostres imaginaris en un grau igual o superior del que formen els autors de la tradició catalana pròpiament dita. En definitiva, a diferència de temps passats, aquesta és una època de total eclecticisme; cap gènere ni cap forma està mal vist ... si està ben fet.

El dramaturg encara jove més traduit i representat per tota Europa i Amèrica és Sergi Belbel. Va començar a escriure des de la més dura experimentació $i$ ara presenta obres d'intenció i de tècniques atrevides, però capaces de ser rebudes $i$ enteses per un públic ampli. $\mathrm{Al}$ seu costat, però, de moment, en grau més modest, han traspassat fronteres autors d'escriptura complexa com Lluïsa Cunillé o Carles Batlle. També han traspassat fronteres lingüístiques autors d'obres i d'intenció més directament popular com Jordi Galzeran o Jordi Sànchez. En tot cas, els escriptors citats i molts altres que no he citat, tant els de les darreres generacions com aquells que sobreviuen de generacions anteriors, configuren un mosaic que omple tota la gamma d'allò que anomenem normalitat.

Som, pel que sembla, a la terra promesa. Hem de cultivar els seus fruits amb entusiasme $i$ amb suors, patint quan s'acosta la tempesta $i$ feliços quan brilla el sol. En definitiva, treballem per guanyar-nos aquesta mena de terra que, per a nosaltres, és el teatre.

JOSEP MARIA BENET I JORNET 